\title{
Uusien jalostusmenetelmien käytön kannattavuus lypsykarjatilalla - lyhyen aikavälin tarkastelu
}

Leena Kärkkäinen ${ }^{1}$, Timo Sipiläinen ${ }^{1}$, Jarmo Juga ${ }^{2}$, Hilkka Kämäräinen ${ }^{3}$

1. Helsingin yliopisto, Taloustieteen laitos, PL 27, 00014 Helsingin yliopisto, leena.karkkainen(at)helsinki.fi, timo.sipilainen(at)helsinki.fi

2. Helsingin yliopisto, Maataloustieteiden laitos, PL 27, 00014 Helsingin yliopisto, jarmo.juga(at)helsinki.fi

3. Savonia ammattikorkeakoulu, PL 72, 74101 Iisalmi, hilkka.kamarainen(at)savonia.fi

\section{TIIVISTELMÄ}

Uusilla jalostusmenetelmillä voidaan nopeuttaa karjan perinnöllistä edistymistä, mutta niiden käyttö myös lisää kustannuksia. Tässä tutkimuksessa selvitettiin genomisen valinnan ja sukupuolilajitellun siemenen käytön taloudellista kannattavuutta lypsykarjatilalla. Tarkastelukulmana oli karjan sisäisen lehmävalinnan tehostaminen. Tutkimuksessa arvioitiin, saadaanko lisäpanostus jalostukseen takaisin nettotuottoina lyhyellä, viiden vuoden tarkasteluperiodilla.

Tutkimus toteutettiin yhteistyössä Savonia ammattikorkeakoulun Maili-hankkeen kanssa ja tutkimuksessa oli mukana pohjoissavolaisia maitotiloja C2-tukialueelta. Tiloja oli yhteensä 15 ja ne olivat noin 30-, 65- ja 130-lehmän karjoja.

Tutkimusmenetelmänä käytettiin nettonykyarvolaskentaa, jossa nettokassavirrat diskontattiin nykyhetkeen, koska tulot ja menot kertyivät eri ajankohtina. Korkokantana käytettiin 5 prosenttia. Kannattavuutta laskettiin osittaisbudjetointina, jossa otettiin huomioon kassavirrat, joihin jalostusmenetelmät vaikuttavat.

Tutkimuksessa käytettiin Illumina Bovine54K- ja Illumina Bovine3K-lastujen arvosteluvarmuuksia, koska Illumina Bovine10K-lastun arvosteluvarmuus ei ollut tutkimushetkellä saatavilla. Hintoina on käytetty 54K- ja 10K-lastujen hintoja. Sukupuolilajitellun siemenen käytöllä pystyttiin vaikuttamaan valinnan ankaruuteen. Tällöin tarvittiin pienempi määrä lehmiä ja hiehoja tuottamaan uudistukseen tarvittavat eläimet, koska lehmävasikoiden todennäköisyys nousi lajitellun siemenen ansiosta 49 prosentista 90 prosenttiin.

Uusien jalostusmenetelmien vaikutusta tutkittiin arvioimalla niiden aikaansaamaa muutosta maitotuotokseen, hedelmällisyyteen, utareterveyteen ja kestävyyteen yhden valintakierroksen aikana. Kustannukset ja tuotot laskettiin valintavuoden lisäksi viidelle seuraavalle vuodelle, jolloin valinnasta syntyvien jälkeläisten oletettiin tuottavan karjassa kolme tuotosvuotta. Maitotuotoksen muutoksessa huomioitiin muuttuva rehuntarve ja työmäärä. Navetan täyttöasteen oletettiin lehmien osalta pysyvän vakiona. Tarkasteluajanjakso valittiin seuraamaan nopeaa takaisinmaksua, eikä perinnöllisen muutoksen kumulatiivista vaikutusta huomioitu. Myös jalostuseläinkauppa oli tästä tarkastelusta rajattu pois.

Tämän tutkimuksen mukaan uudet jalostusmenetelmät eivät olleet kannattavia vuoden 2013 hintatason mukaan. Lajitellun siemenen käyttö ei ollut kannattavaa, koska sitä käytettäessä sonnivasikoiden määrä väheni ja sitä kautta välitysvasikkatulot pienenivät. Tilojen kannattaisi maksaa lajitellusta siemenannoksesta keskimäärin 5,50 euroa alhaisempaa hintaa kuin lajittelemattomasta siemenannoksesta. Lajiteltua siementä käytettäessä liharoturisteytyssiemennyksiä voitiin lisätä noin 8 prosenttiyksikköä. Ilman lihasonnien käytön lisäämistä lajitellun siemen käyttö oli enemmän kannattamatonta.

MD-lastulla genomisen valinnan kannattava enimmäishinta oli 36-43 euroa riippuen siitä, tehtiinkö määritettävissä eläimissä esivalintaa. LD-lastulla vastaavat enimmäishinnat olivat 34-41 euroa. Lajitellun siemenen käyttö yhdessä genomisen valinnan kanssa ei muuttanut MD-lastun enimmäishintoja, mutta LD-lastun kanssa enimmäishinnat putosivat 30-36 euroon.

\section{Asiasanat}

Lypsykarja, genominen valinta, sukupuolilajiteltu siemen, nettonykyarvo, osittaisbudjetointi 


\section{Johdanto}

Jalostusmenetelmällä tarkoitetaan niitä keinoja, joilla jalostustavoitteisiin pyritään. Tässä tutkimuksessa mukana olleet menetelmät olivat genominen valinta ja sukupuolilajitellun siemenen käyttö. Genomisessa valinnassa nuorille eläimille voitiin laskea jalostusarvon ennusteet niiltä määritettyjen SNPmerkkien perusteella käyttämällä hyväksi ennusteyhtälöitä, jotka oli laskettu ns. referenssipopulaatiosta, joka lypsykarjalla koostuu jälkeläisarvostelluista ja genotyypitetyistä sonneista (Schaeffer 2006, 218). Nuorille eläimille saatiin siten jalostusarvot jo ennen kuin niillä oli omia näyttöjä tai jälkeläisiä. SNP-merkkien tutkimiseen käytettiin erilaisia lastuja, joiden tiheydestä ja referenssipopulaation koosta riippuu saatavien jalostusarvojen arvosteluvarmuus.

Siemenen sukupuolilajittelu oli jalostusmenetelmä, jossa siementä käsiteltiin esimerkiksi virtaussytometrissä ja saatiin eroteltua X- ja Y-kromosomin sisältävät siittiöt niiden erilaisen DNAmäärän perusteella. Pohjoismaissa oli tutkimushetkellä käytössä X-siementä, joka tuotti lehmävasikoita 90 prosentin todennäköisyydellä tai $\mathrm{Y}$-siementä, joka tuotti sonnivasikoita 85 prosentin todennäköisyydellä (Seidel 2003, 586).

Tämän tutkimuksen tavoitteena oli selvittää, parantaako sukupuolilajitellun siemenen ja genomisen valinnan käyttö lypsykarjatilan taloudellista tulosta. Samoin haluttiin selvittää, mahdollistaako sukupuolilajitellun siemenen käyttö liharoturisteytysten lisäämiseen. Tutkimus tehtiin yhteistyössä Savonia ammattikorkeakoulun hallinnoiman Maili-hankkeen kanssa. Maili-hanke tähtäsi kilpailukyvyn ja ympäristötehokkuuden lisäämiseen maidon- ja lihantuotannossa Pohjois-Savossa.

Lypsykarjan jalostussuunnittelussa perinnölliseltä tasoltaan heikoimmat suositeltiin siemennettäväksi liharotuisella sonnilla, jolloin niistä ei jäisi jälkeläistä kasvamaan lypsylehmäksi. Mitä enemmän lehmiä karsittiin lypsyrotuisten vasikoiden tuottamisesta siementämällä ne liharotuisella sonnilla, sitä nopeampaa oli perinnöllinen edistyminen karjan jalostuksessa. Karsintaan vaikutti karjan uudistukseen tarvittavien lehmävasikoiden lukumäärä, joka puolestaan on riippuvainen karjan lehmien poistotahdista. (Haltia ym. 1999, 148-149.) Sukupuolilajitellun siemenen käyttö mahdollisti liharoturisteytyssiemennysten lisäämisen lypsykarjassa.

\section{Aineisto ja menetelmät}

Tutkimuksessa oli mukana pohjoissavolaisia maitotiloja C2-tukialueelta. Tiloja oli yhteensä 15 ja ne olivat noin 30-, 65- ja 130-lehmän karjoja. 30 lehmän karjat edustivat tämän hetken keskivertokokoa ja näillä tiloilla oli parsinavetta. Isommat karjat olivat pihattoja, joissa oli automaattinen lypsyjärjestelmä.

Pohjatietoina käytettiin tilojen vuoden 2012 tuotosseurannan ja kirjanpidon tietoja. Tutkimustilojen keskituotos oli keskimäärin $9834 \mathrm{~kg}$ sekä jalostusarvojen ja odotusarvojen keskiarvo oli 4,2. Uudistusprosentti oli tutkimustiloilla keskimäärin 29,8 , vasikkakuolleisuus 7,5 prosenttia ja siemennyksiä yhtä poikimista varten tarvittiin tiloilla keskimäärin 2,0. Tilojen eläinten keskimääräiset rotuosuudet olivat 43,1 prosenttia ayrshirejä, 56,2 prosenttia holsteineja ja 0,7 prosenttia muita rotuja. Maitolitran hinta oli keskimäärin 0,449 euroa ilman tukia ja säilörehun tuotantokustannus 171 euroa kuivaainetonnia kohti, kun tuet eivät olleet hinnassa mukana. Rehukustannus lisämaitokilogramman tuottamiseen oli keskimäärin 0,129 euroa.

Tutkimusmenetelmänä käytettiin tilakohtaista nettonykyarvolaskentaa, jossa investointien kannattavuutta arvioitiin rahavirroilla. Nykyarvomenetelmällä laskettiin tulo-odotusten nykyarvo ja sitä verrattiin investoinnin aiheuttamiin kustannuksiin. Jos nykyarvoon diskontatut tuotot ylittivät hankintakustannukset, oli investointi kannattava. (Leppiniemi 2005, 20-22.)

Tarkastelussa käytettiin osittaisbudjetointia, jossa otettiin huomioon kassavirrat, joihin jalostusmenetelmät vaikuttivat. Osittaisbudjetoinnilla tutkittiin muutoksia, jotka tapahtuivat tilan tai tuotantosuunnan sisällä. Muutoksia oli neljänlaisia: lisääntyneet tulot, vähentyneet kustannukset, vähentyneet tulot ja lisääntyneet kustannukset. Muutoksen tekeminen oli kannattavaa, mikäli lisääntyneet tulot ja vähentyneet kustannukset olivat suuremmat kuin vähentyneet tulot ja lisääntyneet kustannukset. Osittaisbudjetointi on staattinen laskentamenetelmä, joka kuvaa tutkittavaa asiaa deterministisesti. (Niemi 2002, 22-24.) Tässä tutkimuksessa determinismi tuli esille siinä, että saatiin yksi vaihtoehto, joka oli keskiarvo mahdolliselle muutokselle karjojen perinnöllisessä tasossa. Staattisuutta oli puolestaan se, että simuloinnissa oli mukana vain yksi valintakierros ja sen vaikutukset. 
Uusien jalostusmenetelmien vaikutusta tutkittiin ottamalla huomioon karjan perinnöllisen tason nousun aikaansaama muutos maitotuotokseen, hedelmällisyyteen, utareterveyteen ja kestävyyteen. Perinnöllinen muutos eri ominaisuuksissa laskettiin kertomalla kyseisin ominaisuuden indeksipisteiden muutos jalostusarvojen ennusteiden hajonnalla (Pedersen Aamand 2013, 22-54). Eläimille, joilla oli saatavilla pelkästään odotusarvoindeksi, laskettiin osaindeksit pohjoismaisen kokonaisjalostusarvon ja ominaisuuksien välisten korrelaatioiden perusteella (Pedersen Aamand 2013, 13). Hedelmällisyysindeksi jakautui kolmeen ominaisuuteen: siemennysten määrä, aika poikimisesta ensimmäiseen siemennykseen ja aika ensimmäisestä siemennyksestä viimeiseen siemennykseen. Karjakohtaisen vaikutuksen laskennassa käytettiin hedelmällisyysindeksin ja ominaisuuksien välisiä korrelaatioita (Pedersen Aamand 2013, 31).

Maitotuotoksen, utareterveyden ja siemennysten hintoina käytettiin tilojen kirjanpitoon perustuvia tilakohtaisia hintoja. Maitotuotoksen muutoksessa huomioitiin muuttuva rehuntarve ja ihmistyönmäärä, joka on huomioitu 14,5 euron tuntihinnalla. Maidon hinnassa huomioitiin C2-alueen tuotantotuki. Navetan täyttöasteen lehmien osalta oletettiin pysyvän vakiona.

Genomisen valinnan käytön kannattavuuden laskeminen perustui erilaisiin arvosteluvarmuuksiin odotusarvon ja genomisen jalostusarvon välillä. Genomisen valinnan aikaansaama muutos laskettiin kaavasta:

$$
R=i *\left(P_{G S}-P_{P A}\right) * \sigma_{H},
$$

missä $R$ oli muutoksen suuruus, $i$ valintaero, $P_{G S}$ genomisen valinnan arvosteluvarmuus, $P_{P A}$ odotusarvon arvosteluvarmuus ja $\sigma_{H}$ kokonaisjalostusarvon hajonta (Calus ym. 2013,10). Valintaero saatiin laskemalla valittujen osuus koko karjan eläinmäärästä ja muuntamalla se hajonnan yksiköksi normaalijakauman mukaan (Ojala 1999, 85). Odotusarvon arvosteluvarmuutena käytettiin tässä tutkimuksessa 0,15 (Calus ym. 2013, 10; Bijma 2012, 348). Ayrshire-rodun genomisen arvostelun 54K- eli MD-lastun arvosteluvarmuus laskettiin luotettavuuden neliöjuuresta 0,32 (Makgahlela ym. 2013, 10). Luotettavuudesta saatiin ayrshire-rodun arvosteluvarmuudeksi 0,57. Holstein-rodun luotettavuus oli tutkimuksen mukaan 0,57 (Liu ym. 2013, 41). Tästä saatiin arvosteluvarmuudeksi 0,76. Koska 10Klastun arvosteluvarmuudesta ei ollut tutkimushetkellä tietoa, käytettiin 3K-lastun tietoja. 10K-lastun arvosteluvarmuus on todennäköisesti hieman korkeampi kuin 3K-lastun. 3K-lastun arvosteluvarmuus laskettiin ayrshire-rodulla Ma, Brøndum, Zhang, Lund \& Su (2013, 4670) tutkimustuloksen mukaan siten, että 3K-lastun luotettavuus oli 93,7 prosenttia 54K-lastun luotettavuudesta. Holsteinilla 3Klastun arvosteluvarmuus laskettiin Chen, Liu, Reinhardt \& Reents $(2011,51)$ tutkimustuloksen mukaan, jonka perusteella luotettavuus oli 6,5 prosenttiyksikköä alhaisempi. Hajonnan arvo oli kymmenen (Pedersen Aamand 2013, 60). Genomimäärityksen hintoina käytettiin 54K-analyysin hintaa 80 euroa. Tämä hinta perittiin karva- tai verinäytteestä. 10K-lastun analyysihinta oli puolestaan 55 euroa. (Faba 2013.)

Lajitellun siemenen käytön kannattavuutta osittaisbudjetoinnilla laskettaessa huomioitiin valintaeron muutos valittujen osuuden pienentyessä. Lajitellun siemenen hinta on korkeampi suhteessa tavanomaiseen siemeneen. Hedelmällisyyteen lajiteltu siemen vaikutti siten, että tarvitaan enemmän siemennyksiä ja poikimaväli pitenee (Heikkilä \& Peippo 2012, 3). Siemennyksen hintana käytettiin tilan keskimääräistä siemennyshintaa vuonna 2012. Tyhjäkauden taloudellisena arvona käytettiin Toivakan $(2006,69)$ tutkimuksen arvoja, jotka muutettiin vuoden 2012 hintatasoon.

Lajitellun siemenen käytön kannattavuutta laskettaessa huomioitiin mahdollisuus lisätä liharotusiemennyksiä lehmillä, joilta ei tarvita uudistukseen lypsyrotuista vasikkaa. Kustannuksissa huomioitiin myös poikimavaikeuden ja kantoajan muutos liharotuista sonnia lypsyrotuiselle käytettäessä. Poikimavaikeuden muutoksena käytettiin vuoden 2012 tuotosseurannan poikimatietoja, joiden mukaan kahden tai useamman henkilön vetoapua vaativia poikimisia oli liharotuisilla siemennettäessä 1,1 prosenttiyksikköä enemmän kuin lypsyrotuisilla siemennettäessä. Vasikkakuolleisuuteen käytetyn sonnin rodulla ei näyttänyt olevan vaikutusta vuoden 2012 suomalaisen tuotosseurantatilaston mukaan. Liharotuisten pidempi kantoaika laskettiin painotettuna keskiarvona rotujen käytön suhteessa. Näin laskettuna kantoaika oli 5,6 vuorokautta pidempi liharotuisella kuin lypsyrotuisella. Liharoduilla siemennetyistä lypsyrotuisista lehmistä poistui vuoden 2012 tuotosseuranta-aineiston mukaan 31 prosenttia ennen poikimista. Tämä otettiin huomioon syntyvien vasikoiden määrässä ja sitä kautta välitysvasikoista saatavissa tuloissa. 


\section{Tulokset ja tulosten tarkastelu}

Sukupuolilajitellun siemenen käyttö ei ollut kannattavaa missään karjakokoluokassa (taulukko 1). Lisääntyneet tuotot ja vähentyneet kustannukset eivät riittäneet kattamaan vähentyneitä tuottoja ja lisääntyneitä kustannuksia. Suurimmat tulokseen vaikuttavat erät olivat lajitellun siemen käytöstä aiheutuvat lisääntyneet kustannukset ja vähemmistä sonnivasikoiden määrästä aiheutuvat vähentyneet tuotot välitysvasikoiden myynnistä. Kokonaisjalostusarvo NTM muuttui tutkimustiloilla keskimäärin $+0,77$ pistettä lehmää kohti. Tuotosindeksin muutos oli $+0,32$, utareterveysindeksin $+0,35$, kestävyysindek$\sin +0,48$ ja hedelmällisyysindeksin $+0,24$.

TAULUKKO 1. Sukupuolilajitellun siemenen käytön kannattavuus yhdellä valintakierroksella euroa/tila

\begin{tabular}{lccccc}
\hline Tilat & $\begin{array}{c}\text { Lisääntyneet } \\
\text { tuotot }\end{array}$ & $\begin{array}{c}\text { Vähentyneet } \\
\text { kustannukset }\end{array}$ & $\begin{array}{c}\text { Vähentyneet } \\
\text { tuotot }\end{array}$ & $\begin{array}{c}\text { Lisääntyneet } \\
\text { kustannukset }\end{array}$ & Yhteensä \\
\hline 30 & 493,88 & 90,21 & $-422,23$ & $-581,90$ & $-420,04$ \\
65 & 790,46 & 295,66 & $-926,13$ & $-1028,30$ & $-868,30$ \\
130 & 2011,37 & 495,24 & $-2078,23$ & $-2447,73$ & $-2019,35$ \\
\hline Keskimäärin & 1098,57 & 293,70 & $-1142,20$ & $-1352,64$ & $-1102,57$ \\
\hline
\end{tabular}

Lajitellun siemenen kannattavuus lehmää kohti laskettiin jakamalla taulukon 1 viimeinen luku "yhteensä" karjan keskilehmäluvulla (taulukko 2). Näin tuloksia voitiin vertailla eri karjakokoluokissa. Lajitellun siemenen käytön kannattavuus lehmää kohti heikkeni siirryttäessä kookkaimpiin karjoihin. Käytön kannattavuus heikkeni edelleen, jos liharoturisteytysten käyttömahdollisuuden lisäystä ei huomioitu. Jos liharoturisteytysten aikaansaamiseksi käytetään Y-lajiteltua siementä sonnivasikoiden todennäköisyyden lisäämiseksi, käytön kannattavuus heikkeni edelleen. Sukupuolilajitellun lihasonnisiemenen käytön kannattavuus oli heikointa isoimmissa tutkimuskarjoissa. Liharoturisteytyssiemennyksiä voitiin tutkimuskarjoissa lisätä 8 prosenttiyksikköä lajitellun siemenen ansiosta. Lajitellusta siemenannoksesta tilat pystyivät maksamaan 5 euroa alempaa hintaa kuin lajittelemattomasta siemenestä.

TAULUKKO 2. Sukupuolilajitellun siemenen kannattavuus tutkimustiloilla karjakokoluokittain lehmää kohti

\begin{tabular}{lccc}
\hline Tilat & $\begin{array}{c}\text { Lajiteltu } \\
\text { siemen }\end{array}$ & $\begin{array}{c}\text { Lajiteltu siemen, } \\
\text { ilman lihasonnia }\end{array}$ & $\begin{array}{c}\text { Lajiteltu siemen ja } \\
\text { Y-lajiteltu lihasonnin siemen }\end{array}$ \\
\hline 30 & $-12,90$ & $-15,68$ & $-18,53$ \\
65 & $-13,89$ & $-16,12$ & $-18,18$ \\
130 & $-15,76$ & $-19,04$ & $-23,25$ \\
\hline Keskimäärin & $-14,18$ & $-16,94$ & $-19,99$ \\
\hline
\end{tabular}

Genomisen valinnan käyttö jalostusmenetelmänä ei ollut kannattavaa tutkimustiloilla missään karjakokoluokassa, kun arvosteluvarmuus ja määrityshinta olivat 54K- eli MD-lastun mukaan. Lisääntyneet tuotot ja vähentyneet kustannukset eivät riitä kattamaan lisääntyneitä kustannuksia. 65-lehmän karjoissa vähentyneet kustannukset olivat muita ryhmiä suhteellisesti suuremmat. Lisääntyneet tuotot ja lisääntyneet kustannukset noudattavat samaa linjaa kokoluokkien välillä. Genomisen valinnan käytön vaikutus jalostusarvoihin oli suurempi kuin sukupuolilajitellulla siemenellä. Kokonaisjalostusarvo NTM:n muutos oli keskimäärin $+1,13$ lehmää kohti, tuotosindeksin $+0,51$, utareterveysindeksin $+0,52$, kestävyysindeksin $+0,72$ ja hedelmällisyysindeksin +0.41 .

Kannattava enimmäishinta genomimääritykselle laskettiin vähentämällä kannattavuuden arvoista määrityskustannukset ja jakamalla saatu luku määritettävien lukumäärällä (taulukko 3). Tiloille kannattava enimmäishinta oli keskimäärin 36 euroa. Kun genomimääritysten lukumäärää vähennettiin niin, että määritys tehtiin vain vasikoista, joiden odotusarvot olivat nollan ja +15 välillä, tilojen kannatti maksaa yhdestä määrityksestä hieman korkeampaa hintaa. Keskimäärin enimmäishinta oli silloin 43 euroa. 
TAULUKKO 3. MD-genomimäärityksen kannattava enimmäishinta määritettävää eläintä kohti karjakokoluokittain ja keskimäärin

\begin{tabular}{lcc} 
Tilat & Enimmäishinta & Enimmäishinta, vähemmän genominäytteitä \\
\hline 30 & 32,09 & 41,11 \\
65 & 37,98 & 47,03 \\
130 & 37,54 & 42,06 \\
\hline Keskimäärin & 35,87 & 43,40 \\
\hline
\end{tabular}

Genomisen valinnan MD-lastun ja sukupuolilajitellun siemenen yhteiskäyttö ei ollut kannattavaa tutkimustiloilla missään karjakokoluokassa. Genominen valinta ja sukupuolilajiteltu siemen vaikuttivat yhdessä kokonaisjalostusarvo NTM:n $+2,39$, tuotosindeksiin $+1,47$, utareterveysindeksiin $+1,09$, kestävyysindeksiin $+1,52$ ja hedelmällisyysindeksiin $+0,83$.

Tiloille kannattava genomimäärityksen enimmäishinta oli sama kuin pelkällä genomimäärityksellä eli 36 euroa (taulukko 4). Tiloille kannattavasta genominäytteen enimmäishinnasta yhdessä lajitellun siemenen käytön kanssa laskettiin versio, joissa ei käytetä mahdollisuutta lihasonniristeytysten lisäämiseen. Yhdessä versiossa otettiin genominäytteitä vain niistä nuorista eläimistä, joiden odotusarvo oli nollan ja +15 välillä. Lisäksi laadittiin versio, jossa käytettiin liharisteytyssiemennyksiin Y-lajiteltua siementä. Ilman lihasonnien käytön samanaikaista lisäystä nämä jalostusmenetelmät yhdessä toteutettuna johtivat keskimäärin reilua kolmea euroa alhaisempaan kannattavan määrityshinnan enimmäisarvoon, kuin jos lihasonnin käyttöä lisättiin. Jos genomimäärityshinta pidettiin annettuna ja määritettiin lajitellun siemenen kannattava enimmäishinta, se oli 11 euroa alempi kuin lajittelemattomasta siemenestä maksettava hinta. Jos otetaan genominäytteitä vähemmän, kannattava enimmäishinta oli 4 euroa alhaisempi kuin lajittelemattomasta siemenestä.

TAULUKKO 4. MD-genomimäärityksen kannattava enimmäishinta määritettävää eläintä kohti, kun samalla käytetään lajiteltua siementä

\begin{tabular}{lcccc}
\hline Tilat & $\begin{array}{c}\text { Enimmäis- } \\
\text { hinta }\end{array}$ & $\begin{array}{c}\text { Ilman } \\
\text { lihasonnia }\end{array}$ & $\begin{array}{c}\text { Vähemmän } \\
\text { genominäytteitä }\end{array}$ & $\begin{array}{c}\text { Y-lajiteltu } \\
\text { lihasonnin siemen }\end{array}$ \\
\hline 30 & 38,27 & 34,19 & 48,49 & 31,42 \\
65 & 38,37 & 36,30 & 47,96 & 36,95 \\
130 & 31,23 & 27,62 & 31,22 & 14,17 \\
\hline Keskimäärin & 35,96 & 32,70 & 42,56 & 27,51 \\
\hline
\end{tabular}

Kannattavan genomimäärityksen enimmäishinta oli 34 euroa määritettävää eläintä kohti, kun genomimääritys tehtiin LD-lastulla (taulukko 5). Kun genomimääritysten lukumäärää vähennettiin niin, että määritys tehtiin vain niistä vasikoista, joiden odotusarvot olivat nollan ja +15 välillä, tilat pysyivät maksamaan yhdestä määrityksestä hieman korkeampaa hintaa. Kaikkien tilojen keskiarvo oli 41 euroa. 
TAULUKKO 5. LD-genomimäärityksen kannattava enimmäishinta määritettävää eläintä kohti karjakokoluokittain ja keskimäärin

\begin{tabular}{lcc}
\hline Tilat & Tiloille kannattava hinta & $\begin{array}{c}\text { Tiloille kannattava hinta, } \\
\text { vähemmän genominäytteitä }\end{array}$ \\
\hline 0 & 30,46 & 38,97 \\
65 & 35,75 & 45,26 \\
130 & 35,45 & 40,22 \\
\hline Keskimäärin & 33,89 & 41,48 \\
\hline
\end{tabular}

Tiloille kannattava LD-genomimäärityksen enimmäishinta oli 29 euroa, kun sitä käytettiin yhdessä lajitellun siemenen kanssa (taulukko 6). Tiloille kannattavasta LD-genominäytehinnasta yhdessä lajitellun siemenen käytön kanssa laskettiin versioita, joissa ei käytetty mahdollisuutta lihasonniristeytysten lisäämiseen lajitellun siemenen ansiosta. Yhdessä versiossa otettiin genominäytteitä vain niistä nuorista, joiden odotusarvo oli nollan ja +15 välillä. Lisäksi laadittiin versio, jossa käytettiin liharisteytyssiemennyksiin Y-lajiteltua siementä. Mikään näistä versioista ei kata LDgenomimäärityskustannuksia. Jos pidettiin LD-genomimäärityshintaa annettuna ja laskettiin lajitellun siemenannoksen kannattava enimmäishinta, se oli 0,68 euroa korkeampi kuin lajittelemattomasta siemenannoksesta maksettava hinta. Jos genominäytteitä otettiin vähemmän, kannattava enimmäishinta nousi 4 euroa korkeammaksi kuin lajittelemattomasta maksettava hinta.

TAULUKKO 6. Tiloille kannattava genomimäärityksen enimmäishinta LD-lastulla, kun käytetään samalla lajiteltua siementä

\begin{tabular}{lcccc}
\hline Tilat & $\begin{array}{c}\text { Enimmäis- } \\
\text { hinta }\end{array}$ & $\begin{array}{c}\text { Ilman } \\
\text { lihasonnia }\end{array}$ & $\begin{array}{c}\text { Vähemmän } \\
\text { genominäytteitä }\end{array}$ & $\begin{array}{c}\text { Y-lajiteltu } \\
\text { lihasonnin siemen }\end{array}$ \\
\hline 30 & 33,28 & 29,44 & 42,47 & 24,47 \\
65 & 32,81 & 30,70 & 41,13 & 30,12 \\
130 & 22,47 & 18,79 & 30,18 & 8,26 \\
\hline Keskimäärin & 29,52 & 26,31 & 37,92 & 20,95 \\
\hline
\end{tabular}

Tässä tutkimuksessa rajattiin pois jalostuseläinkauppa- Heikkilä ja Peippo $(2012,135)$ tutkimuksen mukaan sukupuolilajitellun siemenen yhdessä alkionsiirron kanssa toi parhaan käyttökatteen. Seidel Jr (2003, 593) oli saanut sukupuolilajitellun siemenen käytön kannattavuuden rajan pysymään positiivisella puolella yhdysvaltalaisesta aineistosta tekemässään tutkimuksessa. Pryce ja Hayes $(2012,181-$ 182) mukaan genomimäärityksen kannattava enimmäishinta oli 50 Australian dollaria. Calus ym. $(2013,9)$ tutkimuksessa tilalle kannattava enimmäishinta oli 40 euroa ja esivalitsemalla hiehot se nousisi 45 euroon. Sukupuolilajitellun siemenen käyttö nosti tilalle kannattavan genomimäärityshinnan 63 euroon ja esivalinnalla se nousi edelleen 105 euroon. Hjortø, Ettema, Kargo, Sørensen, Nørremark ja Fogh $(2013,9)$ tutkimuksen mukaan tiloille kannattava genomimäärityksen enimmäishinta oli 35-40 euroa uudistustahdista riippuen, kun samalla käytettiin lajiteltua siementä.

Tämän suomalaisilla karjoilla tehdyn tutkimuksen tulokset olivat aivan samaa luokkaa genomisen määrityksen tiloille kannattavan hinnan osalta. Sen sijaan tulokset poikkesivat lajitellun siemenen kannattavuuden osalta selvästi Seidel Jr $(2003,593)$ ja Calus ym. $(2013,9)$ tutkimuksista. Hjortø ym. $(2013,9)$ tutkimuksen tulokset ovat lähellä tämän tutkimuksen tuloksia.

\section{Johtopäätökset}

Tämän tutkimukseen mukaan lajitellun siemenen ja genomisen valinnan käyttö lypsykarjan jalostuksessa ei ollut kannattavaa vuoden 2013 hintatasolla, kun hyödyt on laskettu perinnöllisen tason muu- 
toksesta eikä tilalla käydä jalostuseläinkauppaa. Tutkimuksessa haettiin tiloille genomisen määrityksen ja sukupuolilajitellun siemenen kannattavaa hintaa ja nämä olivat huomattavasti vuoden 2013 tasoa alhaisemmat, jos edellytetään, että investointi maksettaisiin viidessä vuodessa.

Osittaisbudjetointi sopii erittäin hyvin jalostusmenetelmien käytön kannattavuuden laskentaa. Tuottojen ja kustannusten muutosten laskeminen antaa selvän kuvan menetelmien kannattavuudesta. Tässä Excel-ohjelmalla tehdyssä laskelmassa tarkastelujaksona oli yhdessä sukupolvessa aikaansaatu muutos. Jos halutaan pidempi tarkastelujakso, on otettava käyttöön useamman sukupolven samanaikaisesti huomioivia menetelmiä kuten geenivirta- tai simulointimenetelmät.

\section{Kirjallisuus}

Bijma, P. 2012. Accuracies of estimated breeding values from ordinary genetic evaluations do not reflect the correlation between true and estimated breeding values in selected population. Journal of Animal Breeding and Genetics 129 345-358.

Calus, M., Bijma, P., van Arendonk, J. \& Veerkamp, R. 2013. Economics of using genomic selection at the farm level. Saatavilla: http://interbull2.slu.se/www/v1/images/stories/nantes/JOINTPDF/S10_1_Calus.pdf. Viitattu 2.10.2013.

Chen, J., Liu, Z., Reinhardt, F. \& Reents, R. 2011 Reliability of Prediction Using Imputed Genotypes for German Holstein: Illumina 3K to 54K Bovine Chip. Interbull Bulletin 44: 51-54. Stavanger. Norway. Saatavilla: https://journal.interbull.org/index.php/ib/article/view/1191/1259. Viitattu 2.10.2013.

Faba. 2013. Hinnasto. Saatavilla: http://www.faba.fi/palvelut/hinnasto. Viitattu 3.6.2013.

Haltia, S., Himanen, A., Hyppänen, K., Juga, J., Korhonen, T., Lampinen, A., Mäntysaari, E., Niskanen, S., Puonti, M., Syväjärvi, J. \& Voutilainen, U. 1999. Tietojen keruu ja käytännön jalostus. Teoksessa: Juga. J., Maijala, K., Mäki-Tanila, A., Mäntysaari, E., Ojala, M. \& Syväjärvi, J. Kotieläinjalostus. s. 97-132. Suo-men Kotieläinjalostusosuuskunta. Vantaa.

Heikkilä, A.-M. \& Peippo, J. 2012. Optimal utilization of modern reproductive technologies to maximize the gross margin of milk production. Animal Reproduction Science 4539. s. 1-10.

Hjortø, L., Ettema, J., Kargo, M., Sørensen, C., Nørremark, T. \& Fogh, A. 2013. Genomic selection strategies for use of genomic tests at herd level. https://www.landbrugsinfo.dk/Kvaeg/Avl/Sider/NAV_Jan2013_workshop_MKS.pdf?download=true. Viitattu 10.9.2013.

Leppiniemi, J. 2005. Rahoitus. 4. uudistettu painos. Werner Söderström Osakeyhtiö. Helsinki.

Liu, Z., Aamand, G.P., Fritz, S. \& Schrooten, C. 2013. Comparison of National Genomic Predictions of EuroGenomics Exchanged Young Bulls. Interbull Bulletin no 47. 2013. s. 38-42.

Makgahlela, M.L., Mäntysaari, E.A., Strandèn, I., Koivula, M., Nielsen, U.S., Sillanpää, M.J. \& Juga, J. 2013. Across breed multi-trait random regression genomic predictions in the Nordic Red dairy cattle. Journal of animal breeding and genetics 130 (2013) 10-19.

Ma, P., Brøndum, R.F., Zhang, Q., Lund, M.S. \& Su, G. 2013, Comparison of different methods for imputing genome-wide marker genotypes in Swedish and Finnish Red Cattle. Journal of Dairy Science 96: $4666-4677$.

Niemi, J.K. 2002. Eläintautiriskien ekonomiaa. MTT:n selvityksiä 12 . Saatavilla: http://www.mtt.fi/mtts/pdf/mtts12.pdf. Viitattu 13.10.2013.

Ojala, M. 1999. Kotieläinjalostuksen perusteet. Teoksessa: Juga. J., Maijala, K., Mäki-Tanila, A., Mäntysaari, E., Ojala, M. \& Syväjärvi, J. Kotieläinjalostus. s. 36-96. Suomen Kotieläinjalostusosuuskunta. Gummerus kirjapaino. Jyväskylä.

Pedersen, J., Sörensen, M.K., Toivonen, M., Eriksson, J-Å. \& Pedersen Aamand, G. 2008. Report on Economic Basis for a Nordic Total Merit Index. Saatavilla: http://www.nordicebv.info/NR/rdonlyres/B618C0E5-FF6F-4D31-8F86-

B3CE4A140043/0/NAV_TMI_report_lastversion_131108.pdf. Viitattu 4.6.2013

S Pryce, J. \& Hayes, B. 2012. A review of how dairy farmers can use and profit from genomic technologies. Animal Production Science 52: 180-184.

chaeffer, L.R. 2006. Strategy for applying genome-wide selection in dairy cattle. Journal of Animal Breeding and Genetics. 123 (2006) s. 218-223. Blackwell Verlag, Berlin.

Seidel, G.E. Jr. 2003 Economic of selecting for sex: the most important genetic trait. Theriogenelogy: 59, 2 (2003). s. 585-598. 